\title{
Seroprevalence and risk factors on Syphilis among blood donors in Chengdu, China,from 2005 to 2017
}

\author{
Shuangli Liu', Liping Luo², Guangxiang Xi ${ }^{3}$, Like Wan ${ }^{4}$ Li Zhong ${ }^{5}$, Xue Chen ${ }^{6}$, Tianxiang Gong ${ }^{7}$, Shuping Li,
} $\mathrm{Yi} \mathrm{He}^{8}$ and $\mathrm{Na} \mathrm{Li}{ }^{7^{*}}$

\begin{abstract}
Background: High-risk population of blood donation increases the prevalence of transmit blood-borne diseases and harm the blood safety. Syphilis accounts for approximately $10 \%$ of commonly sexually transmitted diseases. The risk factors for blood donors infected with syphilis are also risk factors for other blood borne diseases. The objective of the study is to investigate the seroprevalence and risk factors on syphilis among blood donors, and analyze the donation status of high-risk population.
\end{abstract}

Methods: A retrospective study was conducted in Chengdu Blood Center during 2005 and 2017. Serological test results of volunteer blood donors were collected. Conditional logistic regression models were performed to investigate syphilis-related risk factors and population attributable risk (PAR) was performed to predict the tendencies of high-risk populations' on risky behaviors.

Results: The serological epidemic for syphilis among blood donors in Chengdu showed an upward trend from 2005 to 2017.TP positive blood donors were more likely to have multiple sexual partners and commercial sex (50.6\% vs.22.6, $11.1 \%$ vs.4.6\%). Multiple condition logistic regression model denoted the following risk factors for increasing rates of syphilis infections: multiple sexual partners $(\mathrm{OR}=7.1,95 \% \mathrm{Cl}: 1.72-6.58)$, razor reuse $(\mathrm{OR}=1.7$; 95\% Cl:1.01-2.01); ear piercing ( $\mathrm{OR}=2.7,95 \% \mathrm{Cl}: 1.48-3.37)$; tattoo $(\mathrm{OR}=3.3,95 \% \mathrm{Cl}: 1.17-6.78)$; condom occasionally $(\mathrm{OR}=2.8,95 \% \mathrm{Cl}: 0.68-1.66)$. The PAR for each of the risk factors were $0.225,0.144,0.147,0.018,0.129,0.018$, respectively.

Conclusion: Health consultation and screening of high-risk groups before blood donation need to be further improved. Blood donor recruitment should emphasize on excluding the high-risk donors and recruiting more lowrisk blood donors. In addition, this study also shows that sharing cosmetic surgical instrument has been proven to transmit blood-borne diseases. Therefore, the syphilis in blood circulation should not be ignored.

Keywords: Syphilis, Risk factors, Blood safety, Health consultation, Blood donors

\section{Background}

Blood donation is an important procedure that saves millions of lives. However, unsafe transfusion practices carry the risk of transfusion-transmissible infections (TTIs). An unsafe blood transfusion is very costly from both an economic and a human point of view, not only for the recipients themselves, but also for their families and their communities $[1,2]$. In China,

\footnotetext{
* Correspondence: star_blue05@126.com

${ }^{7}$ Blood research laboratory, Chengdu Blood Center, Chengdu, China Full list of author information is available at the end of the article
}

hepatitis $\mathrm{B}$ virus (HBV), hepatitis C virus (HCV), human immunodeficiency virus (HIV) and Treponema pallidum (TP) in all donations must be underwent routine laboratory testing. Syphilis is a sexually transmitted disease (STD), caused by the spirochete Treponema pallidum subsp. pallidum (hereafter Treponema pallidum), is a chronic, sexually transmitted infection affecting an estimated 36 million people worldwide, with 11 million new cases occurring annually [3]. Syphilis is a multistage disease punctuated by asymptomatic periods of latency. The primary and

(C) The Author(s). 2019 Open Access This article is distributed under the terms of the Creative Commons Attribution 4.0 International License (http://creativecommons.org/licenses/by/4.0/), which permits unrestricted use, distribution, and 
secondary stages of syphilis present with a painless chancre at the initial site of infection followed by a non-pruritic rash, respectively, both of which spontaneously resolve [4]. The World Health Organization (WHO) has conducted a survey on the prevalence of four sexually transmitted diseases: chlamydia trachomatis, Neisseria gonorrhoeae, syphilis, and trichomonas vaginalis. It was found that syphilis accounts for approximately $10 \%$ of these sexually transmitted diseases [5, 6]. According to the Chinese Health Statistical Digest by the Chinese Ministry of Health $(\mathrm{MOH})$, the incidence of syphilis is second only to viral hepatitis and tuberculosis in chinese class $\mathrm{A}$ and B communicable diseases [7].

Treponema pallidum can survive for several years at $78^{\circ} \mathrm{C}$, in the blood from syphilis patients may still be infectious within 4 days storage at $-4{ }^{\circ} \mathrm{C}[8,9]$. Syphilis and HIV affect similar patient groups and coinfection is common. Infection with syphilis is a risk factor for infection with HIV, HBV, and HCV [1012]. The risk factors for blood donors infected with syphilis are also risk factors for other blood borne diseases [13-15]. Screening for high-risk groups before blood donation currently depends entirely on pre-donation health consultation. They donate blood or need postpone and withdraw from blood donation depend to the report of blood donors on medical history and dangerous behavior [16, 17]. In fact, many blood donors did not earnestly fill out the "health status inquiry form of blood donors", some of them did not understand the contents of the questionnaire and could not accurately fill out, or concerned about the privacy disclosure in the process of blood donation on a public environment. Moreover, the diversity of blood donation motives also made it impossible for some blood donors to report truthfully, resulting in some high-risk groups entering the blood donation process. For instance, some blood donors may not know that their behaviors are dangerous behaviors which are susceptible to transfusion diseases, or some blood donors who have the clear risky behaviors intentionally concealed to detect whether they are infected. In addition, some blood donors have not read the health checklist carefully in order to save time.

Blood donation in high-risk groups is a threat to blood safety. It is a matter of concern whether the high-risk group of blood donors is effectively excluded from the health consultation before blood donation. In order to optimize donor selection, a validated donor questionnaire should be used and confidentiality in all steps of donation. The possibility of a confidential self-exclusion should be explicitly pointed out to donors. In this study, we conducted a survey on the seroprevalence and risk factors on syphilis among blood donors in Chengdu from 2005 to 2017.

\section{Methods \\ Study subjects}

The blood samples were collected from blood donors in Chengdu from January 2005 to December 2017. Donors with seropositivity of syphilis alone were selected as cases. Controls were matched to cases to control confounding. For each positive case, two syphilis-negative, age- and sex-matched donors were selected as controls. Between January 2005 and December 2017, 368 positive cases and 736 controls were included in the prevalence study. This study was approved by the Medical Ethics Committee of Sichuan University (NO:2014015-02).

\section{Methods}

\section{Laboratory tests}

Blood specimens from the blood donors were tested for HBsAg, anti-HCV, anti-HIV (types 1 and 2), syphilis, and ALT according to procedures stipulated in the Chengdu blood center. The equipment of anti-TP testing: FAME24/20 automatic enzyme immunoassay system (Hamilton, USA). Reagents: anti-TP diagnostic kit (Beijing Wantai, lot number N20110405, N20110708; Beijing Huada love, lot number 20110616, 20110915). Blood specimens were carried out using two different test kits that were approved by the Chinese Food and Drug Administration. Each donation was screened by two ELISA kits regardless of the result of the first one. Each initial reactive sample was further tested in duplicate, according to the manufacturer's instructions. If two out of three results were positive (Repeat Reactive), the unit was discarded and the sample was classified as positive.

\section{Subject questionnaire and data collection}

Donors with anti-TP infection alone were selected as cases. Controls were matched to cases to control confounding. All the selected donors were contacted by telephone obtained from donor registration forms. After explanation of the study aim some blood donors agreed to participate in the study. A risk assessment questionnaire (Additional file 1) was given to every eligible donor in order to investigate relevant information. The main contents of the questionnaire include: the information consisted of facial shaving by sex, age, nationality, occupation, educational level and marital status; related behaviors including sharing razor, tattooing, dental treatment, ear piercing, transfusion, acupuncture, injection, dental treatment, body fluid contact, condom use, paid sex, sexual contact with syphilis patients. The investigation was 
conducted by professional medical personnel in order to ensure the accuracy of data collection. All the information was confidential.

\section{Statistical methods}

Calculated the rate of TP-positive, seroprevalence and serological incidence based on the test results. The rate of TP-positive refers to the proportion of the total number of syphilis-positive in the total blood donations, that is, the total number of syphilispositive as a molecule, and the total population of blood donations as the denominator. Seroprevalence was calculated using the total number of syphilispositive donors as the numerator in the initial blood donation, the total number of initial blood donors at the same period as the denominator. Serological incidence (\%): The total number of syphilis-positive in the repeat blood donors in that year was the numerator, all repeat blood donors during the same period was the denominator. Database was established using Epidata3.1. Data were analyzed using SPSS version 22.0. Possible risk factors for screening of meaningful variables were analyzed by using conditional logistic regression and estimates of the odds ratios (ORs) with their corresponding 95\% confidence interval (CI). The crude odds ratios (ORs) and 95\% CI were estimated by the univariate conditional logistic regression analysis. Potential interactions between razor sharing and tattooing, ear piercing, condom and number of sex partner were assessed. Correlation analyses, such as Spearman rank correlation were also performed for testing collinearity among independent variables. Forward stepwise methods were used to determine which variables significantly contributed to syphilis infection. All of statistical tests were two-sided and a level of $P<0.05$ was used to indicate statistical significance.
The proportion of all the TP-positive cases in the population of the voluntary blood donors attributable to multiple risk factors (population attributable risk, PAR) was estimated by using Bruzzi's formula [18] to the observed OR.

\section{Results}

\section{Seroprevalence and serological incidence}

A total of 2,100,071 voluntary blood donors were selected in the Chengdu blood center during 2005-2017 for the study. It is worth mentioning that all participants in the study have normal levels of transaminase, and HIV, HBV and HCV tests are negative. Of these, 20,510 blood donations were positive for syphilis (Table 1). The rate of anti-TP positivity was $0.88 \%$ corresponding to 815 repeatedly reactive ELISA tests out of 92,610 blood donations in 2005 and the rate of TP-positivity was 0.98 in 2017. The seroprevalence of syphilis in blood donors from 2005 to 2017 in Chengdu also showed an overall upward trend (Fig. 1), while the serological incidence was fluctuated. The seroprevalence of the first-time blood donors in the study period were higher than the serological incidence (Table 1).

\section{Risk factors}

During the case-control study, 368 (33.3\%) of the 1104 eligible anti-TP-positive donors were enrolled in the study. After obtaining informed consent for the study, 368 anti-TP-positive cases and 736 controls were investigated. Reasons for non-response included contact lost and refusing to participate in the study. Overall and subgroup-specific prevalence of T.pallidum seropositivity and active syphilis infection were calculated using case definitions described above. The demographic characteristics associated with all samples were shown in Table 2. Demographic variables included marital status,

Table 1 The seroprevalence of syphilis in Chengdu blood center, 2005-2017

\begin{tabular}{|c|c|c|c|c|c|c|c|c|c|c|c|c|c|}
\hline & 2005 & 2006 & 2007 & 2008 & 2009 & 2010 & 2011 & 2012 & 2013 & 2014 & 2015 & 2016 & 2017 \\
\hline Total number of blood donations & 92610 & 105949 & 121745 & 137524 & 150702 & 145691 & 149863 & 153299 & 160507 & 182222 & 192959 & 205963 & 219140 \\
\hline Number of initial blood donors & 82304 & 86948 & 93272 & 104551 & 110174 & 102357 & 120561 & 134350 & 128455 & 116679 & 117722 & 122212 & 124779 \\
\hline Number of repeat donors & 10306 & 19001 & 28473 & 32973 & 40528 & 43334 & 29302 & 18949 & 32052 & 65543 & 75237 & 83751 & 94361 \\
\hline Total number of syphilis-positive & 815 & 804 & 889 & 1019 & 1302 & 1486 & 1452 & 1825 & 2280 & 1869 & 1709 & 2052 & 2157 \\
\hline $\begin{array}{l}\text { syphilis-positive in the initial } \\
\text { blood donors. }\end{array}$ & 734 & 712 & 796 & 938 & 1119 & 1245 & 1241 & 1541 & 1869 & 1621 & 1516 & 1795 & 1828 \\
\hline syphilis-positive in repeat donors & 81 & 92 & 93 & 81 & 183 & 241 & 211 & 284 & 411 & 248 & 193 & 257 & 329 \\
\hline Rate of TP-Positive(\%) & 0.88 & 0.76 & 0.73 & 0.74 & 0.86 & 1.02 & 0.97 & 1.19 & 1.42 & 1.02 & 0.89 & 1.00 & 0.98 \\
\hline Seroprevalence(\%) & 0.89 & 0.82 & 0.85 & 0.90 & 1.02 & 1.22 & 1.03 & 1.15 & 1.46 & 1.39 & 1.29 & 1.47 & 1.46 \\
\hline serological incidence (\%) & 0.79 & 0.48 & 0.33 & 0.25 & 0.45 & 0.56 & 0.72 & 1.50 & 1.28 & 0.38 & 0.26 & 0.31 & 0.35 \\
\hline$P$ value & 0.282 & $<0.001$ & $<0.001$ & $<0.001$ & $<0.001$ & $<0.001$ & $<0.001$ & $<0.001$ & 0.021 & $<0.001$ & $<0.001$ & $<0.001$ & $<0.001$ \\
\hline
\end{tabular}

Seroprevalence(\%): the seroprevalence was calculated using the total number of syphilis-positive donors as the numerator in the initial blood donation, the total number of initial blood donors at the same period as the denominator. Serological incidence(\%): The total number of syphilis-positive in the repeat blood donors in that year was the numerator, all repeat blood donors during the same period was the denominator 


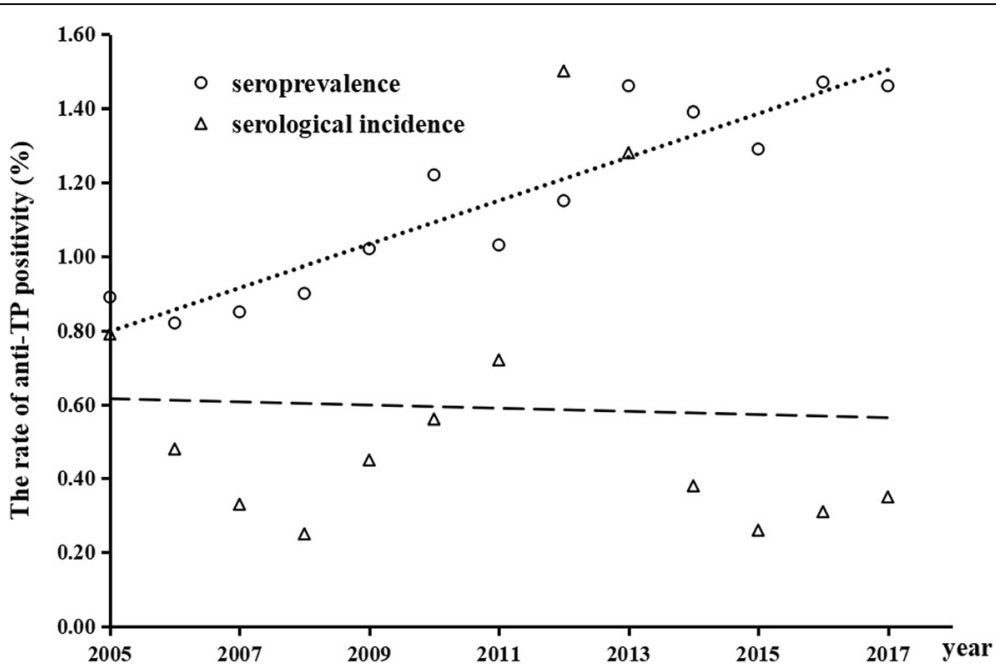

Fig. 1 The linearity of seroprevalence and serological incidence in blood donors from 2005 to 2017 (seroprevalence $R^{2}=0.9011$, serological incidence $R^{2}<0.9$ )

Table 2 Demographic characteristics of the research subject, 2005-2017

\begin{tabular}{|c|c|c|c|c|}
\hline & \multicolumn{2}{|c|}{ Case } & \multicolumn{2}{|c|}{ Control } \\
\hline & NO. & $\begin{array}{l}\text { Percent } \\
(\%)\end{array}$ & NO. & $\begin{array}{l}\text { Percent } \\
(\%)\end{array}$ \\
\hline \multicolumn{5}{|l|}{ Marital status } \\
\hline Single & 93 & 25.3 & 193 & 26.2 \\
\hline Married & 266 & 72.3 & 536 & 72.8 \\
\hline Divorced & 9 & 2.4 & 7 & 1.0 \\
\hline \multicolumn{5}{|l|}{ Education } \\
\hline$<$ Primary school & 34 & 9.2 & 38 & 5.2 \\
\hline Middle school & 123 & 33.4 & 214 & 29.1 \\
\hline High school & 107 & 29.1 & 214 & 29.1 \\
\hline Complete university and above & 104 & 28.3 & 270 & 36.7 \\
\hline \multicolumn{5}{|l|}{ Sex } \\
\hline Male & 177 & 48.1 & 354 & 48.1 \\
\hline Female & 191 & 51.9 & 382 & 51.9 \\
\hline \multicolumn{5}{|l|}{ Occupation } \\
\hline Worker & 59 & 16.0 & 111 & 15.1 \\
\hline Farmer & 46 & 12.5 & 119 & 16.2 \\
\hline $\begin{array}{l}\text { Merchant and commercial } \\
\text { service }\end{array}$ & 95 & 25.8 & 125 & 17.0 \\
\hline Government staff & 40 & 10.9 & 100 & 13.6 \\
\hline Student & 25 & 6.8 & 84 & 11.4 \\
\hline Staff & 38 & 10.3 & 100 & 13.6 \\
\hline Other & 65 & 17.7 & 97 & 13.2 \\
\hline
\end{tabular}

Note: 1) The people of divorced group included widowed and separated. 2) The other group in occupation included unemployed self-employed and others educational attainment, sex, and occupation. In the study, no significant differences were found between the cases and the demographic and socioeconomic characteristics of controls.

By conditional logistic regression, occupation as a risk factor significantly associated with syphilis infection was student, the education was bachelor. Razor reuse, ear piercing, tattoo, dental operation, paid sex, number of sex partner, condom and sexual contact with syphilis $(P<0.05$; Table 3$)$. After the forward stepwise method was used for variable selection in the multiple conditional logistic regression, interaction terms were checked in the final model. It is shown that no statistically significant interactions were found among these variables: occupation and education. Dental operation and paid sex did not show significant associations with syphilis infection $(P>0.05$; Table 4$)$.

Multiple condition logistic regression model denoted the following risk factors for increasing rates of syphilis infections: multiple sexual partners $(\mathrm{OR}=7.1 ; 95 \% \mathrm{CI}=$ $3.685,13.599)$, razor reuse $(\mathrm{OR}=1.7 ; 95 \% \mathrm{CI}=1.252$, 2.261); ear piercing $(\mathrm{OR}=2.7 ; 95 \% \mathrm{CI}=1.877,3.916)$; tattoo $(\mathrm{OR}=3.3$; $95 \% \mathrm{CI}=1.492,7.167)$; condom occasionally $(\mathrm{OR}=2.8 ; 95 \% \mathrm{CI}=1.802,4.399)$. The estimates of the PAR indicated that number of sex partner for syphilis infection accounted for $22.5 \%$ of all TP-positive cases (Table 5). Razor reuse, ear piercing, tattoo, condom, and Sexual contact with syphilis accounted for $14.4,14.7,1.8,12.9,1.8 \%$ respectively (Table 5). However, The estimates of the PAR about uncertain sexual contact with syphilis in TP-positive cases was $8.1 \%$. In fact, $68.78 \%$ of all TP-positive cases occurring in subjects were closely related to these risk factor. The PAR was used to assess the importance of a risk factor among 
Table 3 The result of univariate logistic regression, 2005-2017

\begin{tabular}{|c|c|c|c|c|c|c|c|c|}
\hline Variable & Case $(n=368)$ & Control $(n=736)$ & $\beta$ & SE & $P$ & OR & $95 \% \mathrm{Cl}$ & \\
\hline Marital status (control=single) & $96(25.3)$ & $193(26.2)$ & & & 0.142 & & & \\
\hline Married & $266(72.3)$ & $536(72.8)$ & 0.096 & 0.222 & 0.666 & 1.100 & 0.713 & 1.699 \\
\hline Divorced & $9(2.4)$ & $7(1.0)$ & 1.111 & 0.568 & 0.050 & 3.038 & 0.998 & 9.250 \\
\hline Occupation (control=worker) & $59(16.0)$ & $111(15.1)$ & & & $<0.001$ & & & \\
\hline Farmer & $46(12.5)$ & $119(16.2)$ & -0.321 & 0.255 & 0.208 & 0.725 & 0.440 & 1.196 \\
\hline Merchant and commercial & $95(25.8)$ & $125(17.0)$ & 0.347 & 0.219 & 0.113 & 1.415 & 0.921 & 2.175 \\
\hline Government staff & $40(10.9)$ & 100 (13.6) & -0.310 & 0.263 & 0.238 & 0.733 & 0.438 & 1.228 \\
\hline Student & $25(6.8)$ & $84(11.4)$ & -1.369 & 0.422 & 0.001 & 0.254 & 0.111 & 0.582 \\
\hline Staff & $38(10.3)$ & 100 (13.6) & -0.393 & 0.267 & 0.142 & 0.675 & 0.400 & 1.140 \\
\hline Others & $65(17.7)$ & $97(13.2)$ & 0.186 & 0.239 & 0.438 & 1.204 & 0.753 & 1.925 \\
\hline Education (control=primary school or less) & $34(9.2)$ & $38(5.2)$ & & & 0.001 & & & \\
\hline Middle school & $123(33.4)$ & $214(29.1)$ & -0.510 & 0.269 & 0.058 & 0.601 & 0.355 & 1.017 \\
\hline High school & $107(29.1)$ & $214(29.1)$ & -0.698 & 0.280 & 0.013 & 0.498 & 0.288 & 0.861 \\
\hline > Bachelors & $104(28.3)$ & $270(36.7)$ & -1.038 & 0.288 & $<0.001$ & 0.354 & .201 & 0.623 \\
\hline Razor reuse & $201(54.6)$ & $332(45.1)$ & 0.520 & 0.151 & 0.001 & 1.682 & 1.252 & 2.261 \\
\hline Ear piercing & $129(35.1)$ & $165(22.4)$ & 0.997 & 0.188 & $<0.001$ & 2.711 & 1.877 & 3.916 \\
\hline Tattoo & $17(4.6)$ & $11(1.5)$ & 1.185 & 0.400 & 0.003 & 3.270 & 1.492 & 7.167 \\
\hline Eyebrow tattooing & $44(12.0)$ & $70(9.5)$ & .304 & 0.223 & 0.174 & 1.355 & 0.875 & 2.100 \\
\hline Dental operation & $133(36.1)$ & $207(28.1)$ & 0.381 & 0.139 & 0.006 & 1.463 & 1.114 & 1.921 \\
\hline Acupuncture & $58(15.8)$ & $88(12.0)$ & 0.334 & 0.187 & 0.074 & 1.397 & 0.968 & 2.016 \\
\hline Transfusion & $10(2.7)$ & $18(2.4)$ & 0.105 & 0.394 & 0.789 & 1.111 & 0.513 & 2.407 \\
\hline Body fluid contact & $33(9.0)$ & $52(7.1)$ & 0.244 & 0.228 & 0.284 & 0.783 & 0.501 & 1.225 \\
\hline Paid sex & $41(11.1)$ & $34(4.6)$ & 1.067 & 0.262 & $<0.001$ & 2.907 & 1.738 & 4.861 \\
\hline Number of sex partner (control=0) & $24(6.5)$ & $94(12.8)$ & & & $<0.001$ & & & \\
\hline One statilzed sex partner & $157(42.7)$ & $476(64.7)$ & 0.613 & 0.324 & 0.058 & 1.847 & 0.979 & 3.483 \\
\hline$\geq 2$ & $187(50.8)$ & $166(22.6)$ & 1.957 & 0.333 & $<0.001$ & 7.079 & 3.685 & 13.599 \\
\hline Condom (control=always) & $84(22.8)$ & $234(31.8)$ & & & 0.001 & & & \\
\hline occasional & $143(38.9)$ & $231(31.4)$ & 0.728 & 0.194 & $<0.001$ & 2.071 & 1.414 & 3.031 \\
\hline never & $141(38.3)$ & $271(36.8)$ & 0.519 & 0.187 & 0.006 & 1.680 & 1.163 & 2.425 \\
\hline Sexual contact with syphilis (control=yes) & $19(5.2)$ & $3(0.4)$ & & & $<0.001$ & & & \\
\hline No & $275(74.7)$ & $690(93.8)$ & -2.539 & 0.621 & $<0.001$ & 0.079 & 0.023 & 0.267 \\
\hline Uncertain & $74(20.1)$ & $43(5.8)$ & -0.936 & 0.664 & 0.159 & 0.392 & 0.107 & 1.442 \\
\hline
\end{tabular}

Abbreviations: $\beta$ partial regression coefficient, SE Standard Error, $P$ trend significance, $O R$ The crude odds ratios, $C I$ confidence interval

subjects because it is a function of both the relative risk of exposure to that factor and the prevalence of exposure within the population.

\section{Discussion}

The safety of transfusions has reached a very high level. Still, some residual risks of TTI remain in consultation before blood donation. The susceptible populations of syphilis is the same as HIV, with similar biological and behavioral factors [19]. A similar situation exists in the infection of HBV and HCV. Risk factors for blood donors infected with syphilis are also risk factors for other blood-borne diseases $[20,21]$. In the present study, the rate of TP-positive in primary blood donors was higher than in repeat blood donors among blood donors in Chengdu from 2005 to 2017. WHO noted that HIV can be controlled and facilitated through effective antiretroviral drugs, enabling people living with HIV and those at risk to enjoy a healthy and productive life for a long time $[22,23]$. The risk of transmission of HIV is reduced, and the awareness of prevention is weakened, which may be related to the infection of other sexually transmitted diseases.

With the sexual consciousness becoming more and more open, many people use mobile phone software to find sexual partners, which increases the population of 
Table 4 Multivariate logistic regression, 2005-2017

\begin{tabular}{|c|c|c|c|c|c|c|c|}
\hline Variable & $\beta$ & SE & Z & $P$ & OR & $95 \% \mathrm{Cl}$ & \\
\hline Razor reuse & 0.354 & 0.176 & 4.029 & 0.045 & 1.425 & 1.008 & 2.012 \\
\hline Ear piercing & 0.803 & 0.210 & 14.586 & 0.000 & 2.232 & 1.478 & 3.370 \\
\hline Tattoo & 1.035 & 0.448 & 5.328 & 0.021 & 2.814 & 1.169 & 6.774 \\
\hline Number of sex partner (control=0) & & & 53.998 & $<0.0001$ & & & \\
\hline One statilzed sex partner & -0.030 & 0.325 & 0.008 & 0.928 & 0.971 & 0.513 & 1.836 \\
\hline$\geq 2$ & 1.214 & 0.342 & 12.611 & $<0.0001$ & 3.367 & 1.723 & 6.580 \\
\hline Condom (control=always) & & & 6.911 & 0.032 & & & \\
\hline Occasional & 0.057 & 0.229 & 0.061 & 0.805 & 1.058 & 0.675 & 1.658 \\
\hline Never & 0.480 & 0.228 & 4.419 & 0.036 & 1.616 & 1.033 & 2.528 \\
\hline Sexual contact with syphilis (control=yes) & & & 42.577 & $<0.0001$ & & & \\
\hline No & 1.454 & 0.259 & 31.451 & $<0.0001$ & 4.282 & 2.576 & 7.118 \\
\hline Uncertain & 2.160 & 0.650 & 11.052 & 0.001 & 8.674 & 2.427 & 31.001 \\
\hline
\end{tabular}

Abbreviations: $\beta$ partial regression coefficient, SE Standard Error, $Z$ Chi-square value, $P$ trend significance, OR The crude odds ratios, $C I$ confidence interval

multi-sex partners. Multiple sexual partners is a significant risk factor for syphilis infection. In China, the blood donor selection requirements clearly stipulates that multiple sexual partners cannot donate blood [24]. However, there are still some blood donors who deliberately conceal the facts of their multiple sexual partners and enter the blood donation process after filled out health consultation. In the present study, the behavior of multiple sexual partners in the positive group and the control group were 50.8 and $22.6 \%$, respectively. The increase of the proportion of multiple sexual partners in all blood donors have a major impact on blood safety. Different countries adopt different strategies. The UK (excluding Northern Ireland) reduced its blanket ban on MSM

Table 5 Population attributable risk of 4 factors, 2005-2017

\begin{tabular}{lllll}
\hline Variable & Level & Case & OR & PAR(\%) \\
\hline Razor reuse & 0 & 332 & 1 & \\
Ear piercing & 1 & 201 & 1.425 & 14.4 \\
& 0 & 165 & 1 & \\
Tattoo & 1 & 129 & 2.232 & 14.7 \\
& 0 & 11 & 1 & \\
Number of sex partner $\geq 2$ & 0 & 231 & 1 & \\
& 1 & 173 & 1.616 & 22.5 \\
Condom (occasional) & 0 & 166 & 1 & \\
& 1 & 187 & 3.367 & 12.9 \\
Sexual contact with syphilis & 1 & 3 & 8.674 & 1.8 \\
& 0 & 43 & 1 & \\
Uncertain of sexual contact & 1 & 74 & 4.282 & 8.1 \\
with syphilis & & & & \\
Total PAR(\%) & & & & 76.2 \\
\hline
\end{tabular}

Abbreviations: OR The crude odds ratios, PAR population attributable risk (men who had sex with men) donors to a narrower restriction which only prevents MSM from donating blood if they have had sex with other men within the past year [25]. A similar change was made in the U.S. in late 2015 by the FDA [26]. Countries such as Canada and Norway have extended blood donations for six months after replacing a new sexual partner [27-29]. There is a lack of authoritative interpretation of multiple sexual partner concepts in China, especially for the definition of time. The length of the infection window period is an important factor of blood safety, a scientific strategy can ensure blood safety without affecting the supply of blood resources.

The prevailing viewpoint is that syphilis is a sexually transmitted disease. Actually, in our study, shared razors, ear piercings, and tattoos are also the high risk factors for syphilis infection. Sharing cosmetic surgical instrument has been proven to transmit blood-borne diseases. Currently, cosmetic surgery such as tattooing, piercing, rhinoplasty, injection, laser, and liposuction has greatly increased. [30, 31] It has been reported that $17.27 \%$ of college students have a history of cosmetic surgery such as rhinoplasty, and $69.4 \%$ said they would undergo such cosmetic surgery without considering economic factors [32-34]. Therefore, the blood transmits pathway of syphilis should not be ignored. However, only tattoos and ear piercing have been scheduled to delay be donating blood for one year in China, whereas there is no postponement of blood donation after other cosmetic surgery. The provisions for postponing blood donation after cosmetic surgery should be further improved in future.

Sexual contact with syphilis patients is a highly risk factor for syphilis spread. However, in our survey, many subject are unsure whether their sexual partners were infected with syphilis, the answer between unknown and 
confirm was no statistically significant in multivariate analysis. The reason may be that syphilis patients do not know whether they have been infected with syphilis. The clinical staging of syphilis infection is different, symptoms are complicated. Moreover, the clinical signs of occult infection are not significant, only serological tests are positive, that may cause misdiagnosis and missed diagnosis. The occult infection accounts for about $50 \%$ of the confirmed patients [35, 36]. In addition, the syphilis patients do not recognize the harm of syphilis, or for other reasons, the sexual partner is concealed to her/his sexual partner, and the other partner doesn't have the knowledge to identify syphilis, which may cause widespread spread of syphilis [37]. In our study, considering of privacy, some respondents were reluctant to inform the research investigator about real situation.

Some of the variables in this study were statistically significant in the univariate analysis $(P<0.05)$, indicating that the variable was a risk factor for syphilis infection, but no statistical significance was found in the multivariate analysis, such as paid sexual, condoms, dental history and acupuncture history. It is maybe relate to the biological activity of Treponema pallidum and the size of sample, further research is needed. In this study, paid sexual behavior is also a high risk factor for the spread of syphilis, we included sexual services in the Multiple sexual partners and no longer elaborated. Although the result of marital status was no statistically significant in univariate analysis, in the present study, 9 out of $16 \mathrm{di}$ vorced people were TP positive, and nearly half had paid sexual behavior. The cause of such a high rate of syphilis infection remains to be further studied.

Furthermore, screening for high-risk groups before blood donation is now absolutely dependent on predonation health consultation. Reporting on medical history and risk behavior by blood donors determines that they can donate blood or need to postpone or withdraw from blood donation. In fact, many blood donors did not seriously fill out the "blood donor health status questionnaire". On the one hand, it may be that blood donors didn't understand the contents of the table. On the other hand, some blood donors worried about privacy disclosure when blood was collected on street the open environment. Moreover, the diversity motives of blood donation, also made it impossible for some blood donors to provide true information, therefore, some high-risk groups to enter the blood donation process.

In summary, In order to ensure blood safety and reduce the proportion of blood donation in high-risk groups, it is necessary to strengthen the screening and health survey of blood donors before blood donation. A striking finding of the study is that cosmetic surgery is also one of the risk factors for syphilis infection. Sharing cosmetic surgical instrument which is often overlooked has been proven to transmit blood-borne diseases. Therefore, the blood circulation of syphilis should not be ignored. Moreover, with the rapid development of the economy, the whole country should increase investment in blood collection and supply, and strengthen the promotion of health knowledge. While eliminating high-risk blood donors, it is necessary to ensure that enough low-risk blood donors participate in voluntary blood donation.

\section{Conclusions}

Health consultation and screening of high-risk groups before blood donation need to be further improved. Blood donor recruitment should emphasize on excluding the high-risk donors and recruiting more low-risk blood donors. The seroprevalence of syphilis in blood donors from 2005 to 2017 in Chengdu showed an overall upward trend. However, Chinese $\mathrm{MOH}$ permanently defers donors with TP-positive, thus, the rate of TP-positive in primary blood donors was higher than in repeat blood donors. In addition, this study also shows that sharing cosmetic surgical instrument has been proven to transmit blood-borne diseases. Therefore, the syphilis in blood circulation should not be ignored. The research provides a valuable reference for popularizing syphilisrelated knowledge and is conducive to reducing the risk behaviors of blood donors.

\section{Additional file}

Additional file 1: Questionnaire of Public health (DOCX 14 kb)

\section{Abbreviations}

$\mathrm{Cl}$ : Confidence interval; HBV: Hepatitis B virus; HCV: Hepatitis C virus; HIV: Human immunodeficiency virus; MOH: Ministry of Health; MSM: Men who had sex with men; ORs: The crude odds ratios; PAR: Population attributable risk; STD: Sexually transmitted disease; TP: Treponema pallidum; TTls: Transfusion-transmissible infections; WHO: World Health Organization

\section{Acknowledgments}

We are very grateful to our study participants and the staff of Chengdu blood center. Our sincere gratitude also goes to Professor ShanHua (Stanford Medicine) for her corrections in English grammar and vocabulary in the manuscript.

\section{Authors'contributions \\ S. L. Liu, L. P. Luo, G. X. Xi, Y. He and L. K. Wan designed the study; S. L. Liu, L. P. Luo, G. X. Xi, L. K. Wan, L. Zhong, X. Chen, T. X. Gong, S. P. Li, and N. Li conducted the study, they all took part in the data analysis, interpretation of the data and writing of the manuscript. H. Yi and N. Li drafted the manuscript and all authors reviewed and accepted the final manuscript.}

\section{Funding}

This study was supported by the Science and technology project of Sichuan Province (2015ZR0099). Science and technology department of Sichuan Province had no role in the design of the study, data collection, analysis, interpretation of data or writing of the manuscript.

Availability of data and materials

The datasets used and/or analysed during the current study are available from the corresponding author on reasonable request. 


\section{Ethics approval and consent to participate}

This research work was given an ethical approval by Medical Ethics Committee of Sichuan University (NO:2014015-02). Written informed consent was obtained from all the participants.

\section{Consent for publication}

Not applicable.

\section{Competing interests}

The authors declare that they have no competing interests.

\section{Author details}

'Department of Blood Collection, Chengdu Blood Center, Chengdu, China. ${ }^{2}$ Yibin Blood station, Yibin, China. ${ }^{3}$ Department of Blood Supply, Chengdu Blood Center, Chengdu, China. ${ }^{4}$ Department of Blood Preparation, Chengdu Blood Center, Chengdu, China. ${ }^{5}$ Department of Donor Service, Chengdu Blood Center, Chengdu, China. ${ }^{6}$ Blood Screening Laboratory, Chengdu Blood Center, Chengdu, China. ${ }^{7}$ Blood research laboratory, Chengdu Blood Center, Chengdu, China. ${ }^{8}$ Department of Quality Control, Chengdu Blood Center, Chengdu, China.

Received: 6 November 2018 Accepted: 23 May 2019

Published online: 10 June 2019

\section{References}

1. Greinacher A, Weitmann K, Schonborn L, et al. A population-based longitudinal study on the implication of demographic changes on blood donation and transfusion demand. Blood advances. 2017;1(14):867-74.

2. Yu C, Holroyd E, Cheng Y, Lau JT. Institutional incentives for altruism: gifting blood in China. BMC Public Health. May 30 2013;13:524.

3. Lafond RE, Lukehart SA. Biological basis for syphilis. Clin Microbiol Rev. 2006; 19(1):29-49.

4. Brigette C, Erika W, John R W, Caroline E C. Interaction of Treponema pallidum, the syphilis spirochete, with human platelets. Treponema pallidum-platelet interactions. Jan 18, 2019;14(1):e0210902.

5. Rolfs RT. Treatment of syphilis. Clinical infectious diseases : an official publication of the Infectious Diseases Society of America. Apr. 1995;20(Suppl 1):S23-38

6. Kitayama K, Segura ER, Lake JE, et al. Syphilis in the Americas: a protocol for a systematic review of syphilis prevalence and incidence in four high-risk groups, 1980-2016. Systematic reviews. 2017;6(1):195.

7. Hesketh T, Ye X, Zhu W. Syphilis in China: the great comeback. Emerging health threats journal. 2008;1:e6.

8. Farnes SW, Setness PA. Serologic tests for syphilis. Postgrad Med. 1990;87(3): 37-41 45-36.

9. Harkess JR, Kudlac J, Istre GR. Syphilis, human immunodeficiency virus infection, and targeting prevention. South Med J. Nov 1990;83(11):1253-5.

10. Borobio MV. Syphilis and HIV infection. Enferm Infecc Microbiol Clin. Jan 1990;8(1):7-10

11. Vahdani P, Hosseini-Moghaddam SM, Family A, Moheb-Dezfouli R. Prevalence of HBV, HCV, HIV and syphilis among homeless subjects older than fifteen years in Tehran. Arch Iran Med. Sep 2009;12(5):483-7.

12. Offergeld R, Ritter $\mathrm{S}$, Hamouda O. [HIV, HCV, HBV and syphilis surveillance among blood donors in Germany 2008-2010]. Bundesgesundheitsblatt, Gesundheitsforschung, Gesundheitsschutz 2012;55(8):907-913.

13. Yang T, Chen Q, Li D, et al. High prevalence of syphilis, HBV, and HCV COinfection, and low rate of effective vaccination against hepatitis B in HIVinfected patients in West China hospital. J Med Virol. 2018;90(1):101-8.

14. Salado-Rasmussen K. Syphilis and HIV co-infection. Epidemiology, treatment and molecular typing of Treponema pallidum. Danish medical journal. Dec 2015;62(12):B5176.

15. Niama FR, Loukabou Bongolo NC, Mayengue PI, et al. A study on HIV, Syphilis, and hepatitis $B$ and $C$ virus infections among female sex workers in the republic of Congo. Archives of public health $=$ archives belges de sante publique. 2017;75:21

16. Wiesen B, Kramer H, Meurer A, Stohr C. Ambulatory preoperative autologous blood donation using the leap frog procedure. A report of experiences. Der Chirurg; Zeitschrift fur alle Gebiete der operativen Medizen. 1988;59(9):620-2.
17. Manuel SP, Spitzer TR, Ishizawa Y. Preoperative autologous blood donation in healthy bone marrow donors contributes to pre-procedure anemia. Bone Marrow Transplant. Aug 2017;52(8):1191-3.

18. Bruzzi P, Green SB, Byar DP, Brinton LA, Schairer C. Estimating the population attributable risk for multiple risk factors using case-control data. Am J Epidemiol. Nov 1985;122(5):904-14.

19. Lynn WA, Lightman S. Syphilis and HIV: a dangerous combination. Lancet Infect Dis. Jul 2004;4(7):456-66.

20. McQuillan GM, Townsend TR, Fields HA, Carroll M, Leahy M, Polk BF. Seroepidemiology of hepatitis B virus infection in the United States. 1976 to 1980. Am J Med. 1989:87(3A):5S-10S.

21. Low $E$, Vogel M, Rockstroh J, Nelson M. Acute hepatitis C in HIV-positive individuals. AIDS reviews Oct-Dec. 2008;10(4):245-53.

22. Hamouda LWSRBRROO. HIV, HCV, HBV and syphilis infections among blood donors in Germany 2006. Report from the Robert Koch institute in accordance with article 22 of the transfusion act, vol. 51: Bundesgesundheitsbl - Gesundheitsforsch; 2008. p. 8.

23. Jansen $\mathrm{K}$, Thamm M, Bock $C T$, et al. High prevalence and high incidence of coinfection with hepatitis B, hepatitis C, and Syphilis and Low rate of effective vaccination against hepatitis B in HIV-positive men who have sex with men with known date of HIV seroconversion in Germany. PLoS One. 2015:10(11):e0142515.

24. Zheng X, Ding W, Li G, et al. Seroprevalence of transfusion-transmissible infectious agents among volunteer blood donors between 2006 and 2012 in Zhejiang, China [J]. Blood Transfus. 2015;13(3):1-10.

25. Schmidt AJ, Marcus U. Erratum to: deficits in STI diagnosis for men who have sex with men (MSM) in German-speaking cities [J]. Bundesgesundheitsblatt Gesundheitsforschung Gesundheitsschutz. 2014; 57(3):388-9.

26. "Revised Recommendations for Reducing the Risk of Human Immunodeficiency Virus Transmission by Blood and Blood Products Questions and Answers". US Food and Drug Administration. Archived from the original on 2016-03-30. Retrieved 2016-03-30.

27. Germain M, Robillard P, Delage G, Goldman M. Allowing blood donation from men who had sex with men more than 5 years ago: a model to evaluate the impact on transfusion safety in Canada. Vox Sang. 2014;106(4):372-5.

28. Davison KL, Conti S, Brailsford SR. The risk of transfusion-transmitted HIV from blood donations of men who have sex with men, 12 months after last sex with a man: 2005-2007 estimates from England and Wales. Vox Sang. 2013;105(1):85-8.

29. Choudhri Y, Miller J, Sandhu J, et al. Infectious and congenital syphilis in Canada, 2010-2015[J]. Canada communicable disease report. Canada. 2018; 44(2):43-8.

30. Rajabi MT, Makateb A, Hassanpoor N, et al. Determinative factors in surgical planning of eyebrow cosmetic and reconstructive surgery. Clin Ophthalmol. 2017;11:1333-6.

31. Griffiths D, Mullock A. Cosmetic surgery: regulatory challenges in a global beauty market. Health care analysis : HCA : journal of health philosophy and policy. 2017.

32. Gillen MM, Dunaev J. Body appreciation, interest in cosmetic enhancements, and need for uniqueness among U.S. college students. Body image. 2017;22:136-43

33. Ng JH, Yeak S, Phoon N, Lo S. Cosmetic procedures among youths: a survey of junior college and medical students in Singapore. Singap Med J. 2014; 55(8):422-6.

34. Sarwer DB, Cash TF, Magee $L$, et al. Female college students and cosmetic surgery: an investigation of experiences, attitudes, and body image. Plast Reconstr Surg. 2005;115(3):931-8.

35. Forrest CE, Ward A. Clinical diagnosis of syphilis: a ten-year retrospective analysis in a south Australian urban sexual health clinic. Int J STD AIDS. 2016;27(14):1334-7.

36. Ooi C, Dayan L. Syphilis. Diagnosis and management in general practice. Aust Fam Physician Jul 2002;31(7):629-635.

37. Daskalakis D. Syphilis: continuing public health and diagnostic challenges. Current HIV/AIDS reports. 2008;5(2):72-7.

\section{Publisher's Note}

Springer Nature remains neutral with regard to jurisdictional claims in published maps and institutional affiliations. 